\title{
No Association of LEPR Gln223Arg Polymorphism with LePtin, Obesity or Metabolic Disturbances in Children
}

\author{
B. Pyrzak ${ }^{1}$, A. Wisniewska ${ }^{1}$, A. Kucharska ${ }^{1}$, M. Wasik ${ }^{2}$, U. Demkow ${ }^{2}$ \\ ${ }^{1}$ Department of Pediatrics and Endocrinology and ${ }^{2}$ Department of Laboratory Diagnostics and Clinical Immunology of \\ Developmental Age, Warsaw Medical University, Warsaw, Poland
}

\begin{abstract}
Objective: The aim of the study was to investigate whether the Gln223Arg in the leptin receptor may influence body weight, leptin concentration, and metabolic parameters in children.

Materials and methods: The examined group included 101 obese children (58 girls and 43 boys) with BMI $31.41 \pm 5.03 \mathrm{~kg} / \mathrm{m}^{2}$ (BMI $\geq 2$ SDS) and the control group consisted of 41 children with BMI $20.0 \pm 0.80$ $\mathrm{kg} / \mathrm{m}^{2}$ (BMI <1.0 SDS). Polymorphism identification was performed in total genomic DNA using PCRRFLP method.

Results: The distribution of genotypes LEPR was the following: in the obese group: AA $-20.8 \%$, AG$55.4 \%$, GG-23.8 \%; in the control group AA-31.7\%, AG- 53.65\%, GG-14.65\%.

Comparative analyses between AA homozygous children and carriers of $G$ alleles did not confirm any relation between the analyzed polymorphism and BMI, leptin concentrations, and metabolic disturbances in children with obesity.

Conclusion: In children with obesity we did not observe association of the LEPR Gln223Arg gene polymorphism with obesity, leptin, insulin resistance, and metabolic abnormalities.
\end{abstract}

Key words: polymorphism LEPR Gln223Arg, obesity, leptin, lipids, children

\section{INTRODUCTION}

Obesity is due to the combined effects of genes, environment, lifestyle, and the interactions thereof. Obesity is a major public health concern given the association of this condition with several chronic diseases. Several genes play a major role in obese phenotypes, and studies suggest that genetic variation at the leptin receptor gene locus may play an important role in the pathophysiology of human obesity, which is a leptin resistance state [1]. Some genetic variants increases a person's susceptibility to the common forms of obesity. Identification of the underlying genetic causes of obesity will likely provide a basis both for the development of new therapeutic agents and for the personalized prevention of this condition [2].

Leptin is an adipose-derived cytokine containing 167 amino acids, present in the circulation proportion- al to fat mass that acts to reduce food intake and increase energy expenditure. Defects in leptin production cause severe obesity. Leptin is also known to play a role in different parts of the body, such as the male and female reproductive organs, the mammary gland, bone mineral density, the immune system, the gut, the kidney, and the lung [3].

The LEP gene encodes for leptin, has been localized in humans on the 7 alpha 31.3 chromosome and consists of three exons separated by two introns. Some studies reported a polymorphism in the promoter untranslated exon 1 of the LEP gene (A19G), a polymorphism $\mathrm{C}(-188) \mathrm{A}$ in the promoter region of the LEP gene, and a mutation at codon V110M [4].

The weight regulating effects of leptin are mediated through the binding and activation of the long isoform of its receptor LEPR-b (leptin receptor) in the hypothalamus. The LEPR is a large membrane spanning protein that belongs to the gp 130 family of cytokine class I receptors. LEPR has defined a novel molecular pathway for energy metabolism and regulation of body weight [5]. Some polymorphic genes involved in the regulation of leptin have been investigated as possible factors associated with obesity. LEPR variants commonly occur, which causes two nonconservative changes: lysine to asparagine at codon 656 (AAG to AAC) in exon $14(\mathrm{~K} 656 \mathrm{~N})$; lysine to arginine at codon 109 (AAG to $A G G$ ) in exon 4 (K109R); a non-conservative change glutamine to arginine at codon 223 (CAG to CGG); three silent mutations (nt $1222 \mathrm{~T} \rightarrow \mathrm{C}$, nt $3217 \mathrm{~A} \rightarrow \mathrm{G}$, and nt $3250 \mathrm{G} \rightarrow \mathrm{A}$ ), and four intronic sequence variants [6,7]. Evidence of a significant effect of the Gln223Arg polymorphism on human body composition has been reported in some recent studies $[6,8,9]$. Allelic frequencies of these polymorphisms show ethnic variation, e.g., observed in Caucasian males [9], or in postmenopausal Caucasian women [10]. On the other hand, negative results have been reported for the Gln223Arg polymorphism in the LEPR gene in different Caucasian populations, including American [11], British [12], Danish [13] groups and in Turkish population [14].

The aim of the present study was to evaluate the influence of the Gln223Arg polymorphism in children on body weight, leptin concentration, insulin resistance, and lipid profile. 


\section{MATERIALS AND METHODS}

The Research and Ethics Committee of Warsaw Medical University in Warsaw, Poland approved the study protocol. The examined group included 101 obese children (58 girls and 43 boys) aged $12-18$ years, and the control group of 41 healthy non-obese children (24 girls and 17 boys) aged 12-18 years. A complete history was obtained and thorough physical examination was carried out on all the participants. Height, weight, and blood pressure were measured using standardized equipment. The BMI was calculated as $\mathrm{kg} / \mathrm{m}^{2}$, BMI $\mathrm{z}$-score adjusted for age and sex was calculated using normative data. Obesity was defined as a BMI $z$-score of more than +2 . Waist circumference was adjusted for age and sex and referred on percentile charts. Hip circumference, WHR (waist-to-hip ratio) and sum of the thickness of 3 and 10 skin-folds was measured. The percentage of fat tissue content measured in skin-folds on the arm and below the shoulder blade was calculated using Slaughter's equation [15]. Hypertension was defined as a value of systolic and/or diastolic blood pressure $\geq 95$ th percentile for sex and age. Prehypertension was defined as a value of systolic and/or diastolic blood pressure between the 90-95th percentile.

\section{BiochemicAl Tests}

In the obese children, oral glucose tolerance test (OGT'T) with the measurements of glucose and insulin levels was performed with the use of a standard dose of glucose $(1.75 \mathrm{~g} / \mathrm{kg}$, max. $75 \mathrm{~g}$ glucose). Insulin concentrations were measured by RIA (Radio-Immuno-Assay), plasma glucose level was measured using dry-chemistry method.

Insulin resistance was estimated using fasting plasma insulin homeostasis model assessment HOMA [16]. The oral glucose insulin sensitivity OGIS90 index was calculated from 2-h OGT'T. Plasma total cholesterol (T-chol) and triglycerides (Tg) were determined enzymatically with a Hitachi 912 analyzer (Roche Diagnostics). HDL-cholesterol (HDL-C) was measured using a homogenous method with polyethylene glycolmodified enzymes and alpha-cyclodextrin. LDL-cholesterol (LDL-C) was calculated by the Friedewald equation. Leptin concentrations, measured with RIA (Radio-Immuno-Assay), were adjusted to the referred value of $15-20 \mathrm{ng} / \mathrm{dl}$.

\section{PCR ASSAY}

Genotyping was done using polymerase chain reaction - restriction fragment length polymorphism analyses. Genomic DNA was amplified with specific flanking primers for Gln223Arg in the leptin receptor gene. The primers used in the PCR were: forward $5^{\circ} \mathrm{AAA}$ CTC AAC GAC ACT CTC CT'T $3^{\circ}$ and reverse $5^{\circ}$ TGA ACT GAC ATT AGA GGT GA 3`. The amplified PCR product was digested with the addition Msp I enzymes. The digested samples were separated by electrophoresis and visualized. The identified genotypes were recognized according to the presence or absence of the enzyme restriction sites.

\section{STATISTICAL ANALYSIS}

The Student's t-test for independent and non-independent samples was used to determine the betweengender statistical difference between genders in mean values for each group. Pearson's $\chi^{2}$ test was used to examine differences in characteristic variables and the distribution of genetic polymorphism between the obese and control groups and one-way ANOVA to examine leptin level in children with three variants of genotype. The results were processed statistically using Statgraphics 4.0 plus and STATISTICA 6.0 software. Statistical significance was accepted at a level of $\mathrm{P}<0.05$ [17]. The Hardy-Weinberg equilibrium test was applied to evaluate genotype frequencies [18].

\section{RESULTS}

The obese group consisted of 101 children (58 girls and 43 boys) aged 12-18 years (mean age 15.7) with BMI $31.41 \pm 5.03 \mathrm{~kg} / \mathrm{m}^{2}$ (z-score of BMI $\geq 2$ SDS). The control group consisted of 41 healthy non-obese children (24 girls and 17 boys) aged $12-18$ years (mean age 16) with BMI $20.0 \pm 0.8 \mathrm{~kg} / \mathrm{m}^{2}$ (z-score of BMI $<1.0)$.

In the obese group, all axiological parameters assessing the extent of obesity were elevated: the mean SDS of waist circumference in the obese group was $3.5 \pm 1.4 \mathrm{~cm}$ (above $90^{\text {th }}$ percentile in $90 \%$ girls and in $100 \%$ boys), WHR (waist to hip ratio) was $0.87 \pm 0.08$ $\mathrm{cm}$, sum of 3 skin-fold thickness was $77.5 \pm 2.2 \mathrm{~mm}$, sum of 10 skin-fold thickness was $175.8 \pm 29.5 \mathrm{~mm}$ and the percentage of body fat by Slaughter equation was $36.4 \pm 4.9$. In the assessment of lipid metabolism, the mean of total cholesterol was $175.8 \pm 35.6 \mathrm{mg} / \mathrm{dl}$, HDL-cholesterol was $43.62 \pm 11.9 \mathrm{mg} / \mathrm{dl}$, LDL-cholesterol was $109.2 \pm 28.5 \mathrm{mg} / \mathrm{dl}$, triglycerides were $138.5 \pm 54.8 \mathrm{mg} / \mathrm{dl}$

An analysis of carbohydrate metabolism showed two children in the obese group with diagnosed abnormal fasting glycemia (fasting plasma glucose 100-126 $\mathrm{mg} / \mathrm{dl}), 9$ children with abnormal glucose tolerance (glucose level 2 hour post glucose from 140 to 200 $\mathrm{mg} / \mathrm{dl}$ ), and 2 children with diabetes type 2 (diabetes when two results of fasting plasma glucose levels were above $126 \mathrm{mg} / \mathrm{dl}$ and plasma glucose was above 200 $\mathrm{mg} / \mathrm{dl}$ two hours after standard glucose load).

In 65 children $(64.3 \%)$ fasting insulin concentrations fulfilled the criteria for hyperinsulinism (fasting levels of insulin higher than $15 \mu \mathrm{IU} / \mathrm{ml}$ ) and in 48 children $(47.5 \%)$ insulin concentrations fulfilled the criteria for hyperinsulinism $(120 \mathrm{~min}$ of the OGT'T test insulin peak (post-OGT'T) levels of more than $150 \mu \mathrm{IU} / \mathrm{ml}$ and/or more than $75 \mathrm{mU} / \mathrm{ml}$ at $120 \mathrm{~min}$ of OGTT) [17].

The values of the insulin resistance HOMA demonstrated severe insulin resistance $>3.0$ (in $85 \%$ of children), in consequence the values of the insulin sensitivity index were lowered. In majority of the obese children, the values of systolic blood pressure were higher than the 90th percentile (prehypertension), and in approximately $43 \%$ of them these values were higher than the 95th percentile (hypertension). 


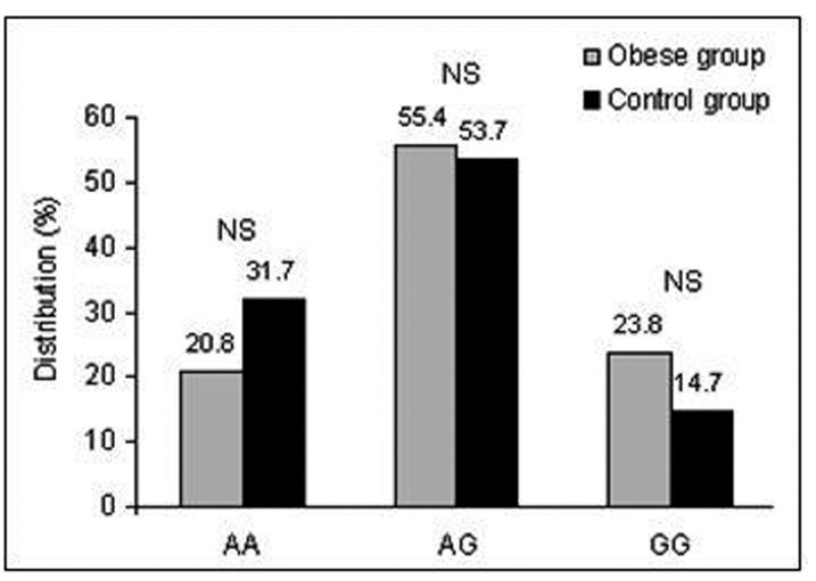

Fig. 1. Distribution of LEPR genotypes in obese children vs control group.

The variants of Gln223Arg (A223G, Q223R) polymorphism in the LEPR gene were the following: homozygous $\mathrm{G} \ln / \mathrm{G} \ln (\mathrm{AA}, \mathrm{Q} / \mathrm{Q})$, heterozygous $\mathrm{G} \ln /$ $\operatorname{Arg}(A G, Q / R)$ and homozygous Arg/Arg (GG, $\mathrm{R} / \mathrm{R})$. The genotype distribution and allele frequencies in all the examined children are presented in Fig. 1. Concerning the distribution of LEPR genotypes, the probability of the incidence of alleles $A$ and $G$ allele in both obese and control groups was in compliance with the Hardy-Weinberg equilibrium. Homozygous GG in the obese group was more frequent than in the control one, but the difference was not statistically significant $\left(\chi^{2}=2.76, \mathrm{NS}\right)$.

A comparative analysis of anthropometric indices, glucose and insulin concentrations, lipids, HOMA, OGIS90, blood pressure, and leptin concentrations did not show statistically significant differences between the children with gene polymorphism and those with the gene polymorphism.

\section{Discussion}

The aim of this study was to evaluate genetically homogeneous children groups for associations between body compositions, lipids, carbohydrate metabolism, blood pressure, leptin, and leptin receptor gene polymorphism and to assess the contributions of these polymorphism to the variability of these indices.

Several single nucleotide polymorphisms in the LEPR gene have been described, but only Gln223Arg and Lys656Asn result in changes of charge (neutral to positive and positive to neutral, respectively) and are, therefore, most likely to have functional consequences. The Gln223Arg polymorphism is within the region encoding the extracellular domain of the leptin receptor and, therefore, the amino acid change affects all forms of the receptor. It has been shown that the LEPR Gln223Arg polymorphism is associated with the variation in ligand binding; higher levels of ligand binding activity have been demonstrated in individuals homozygous for the G (LEPR Arg223Arg) allele than in carriers of the A (LEPR 223Gln) allele [10]. Linkage and association studies between three exonic polymorphisms in the leptin receptor gene and body com- position variables were undertaken in the HERITAGE Family Study. Polymorphism K109 R, Q223R and $\mathrm{K} 656 \mathrm{~N}$ has been analyzed in relation to body mass index (BMI), sum of eight skin-folds (SF8), fat mass $(\mathrm{FM})$, percentage of body fat $(\% \mathrm{FAT})$, fat free mass (FFM), and plasma leptin level in blacks and Caucasians. In Caucasians, BMI and FM showed suggestive associations with Q223R in parents, but not in offsprings. Males, but not females, show differences across genotypes for the same phenotypes plus SF8 and leptin [9].

In another large study, the Quebec Family Study, Chagnon et al [8] investigated the linkage and association between the leptin receptor (LEPR) gene and body composition variables: BMI, sum of six skinfolds, fat mass, percentage of body fat, and free fat mass. The LEPR K109R substitution in exon 4, Q223R in exon 6, K656N in exon 14 were analyzed. The authors did not show significant differences between lower and higher BMI subjects in the genotype and allele frequency distributions for any of the polymorphisms, but showed that the LEPR gene was involved in the regulation of the body composition in humans particularly of FFM in the QFS.

Wauters et al [19] analyzed the relationship between polymorphism in the leptin receptor gene polymorphism Lys109Arg, Gln223Arg and Lys656Asn and body composition as well as fat distribution, including waist and hip circumferences, the amount of visceral and subcutaneous fat in overweight and obese women. They showed that polymorphisms in the leptin receptor gene are associated with a higher mass of abdominal fat in postmenopausal overweight women. Since body fat distribution variables were adjusted for fat mass, their results suggest that DNA sequence variations in the leptin receptor gene play a role in fat topography and may be involved in the predisposition to abdominal obesity. In the majority of studies, there was no evidence of association between the Q223R polymorphism of leptin receptor and obesity. The meta-analysis of the available data [20] on the association between polymorphisms of leptin: the leptin gene (LEP A19G), the leptin receptor gene (LEPR Q223R, $\mathrm{K} 109 \mathrm{R}$, and $\mathrm{K} 656 \mathrm{~N}$ ), and the peroxisome proliferatoractivated receptor-gamma gene (PPARG P12A and C161T) as possible factors associated with obesity, based on case-control studies, suggested no evidence for the association between the genes in question and obesity. Allelic frequencies of these polymorphisms show only ethnic variation. The lack of association could be due to the complex pathogenesis of obesity which involves a numerous of genetic and environmental factors. There are few studies in children. In Japan, Endo et al [21] investigated whether the Gln223Arg polymorphism of the leptin receptor (Ob$\mathrm{R})$ gene was associated with obesity in schoolchildren. They showed that the Gln223Arg polymorphism of the Ob-R gene does not appear to be associated with obesity. Wasik et al [22] investigated Gln223Arg LEPR polymorphism in children with acute leukemia, in which the leptin level is increased and do not find any association with this polymorphism either.

The present results indicate that there was a tendency toward a higher frequency $G$ allele in the group of 
obese children than in the control group; however the difference did not reach statistical significances. Moreover, anthropometric indices, lipids, HOMA, OGIS 90 , blood pressure, and leptin levels did not show significant differences between children with gene polymorphism and wild homozygous genotypes. Although a potential limitation of this study is a moderate sample size, studies evaluating genetic associations in children provide a distinct advantage over those performed in adults.

In summary, polymorphism of the Gln223Arg in children with obesity is appearing with the same frequency as that in non-obese children, and there is no evidence that this mutation plays a role in obesity development or in the pathogenesis of metabolic disturbances in children. The study failed to provide evidence for an association of the LEPR Q223R gene polymorphism in obese children with obesity, lipids, leptin concentrations, or insulin resistance.

\section{REFERENCES}

[1] Djiane J, Attig L. Role of leptin during perinatal metabolic programming and obesity. J Physiol Pharmacol 2008; 59 Suppl 1: 55-63.

[2] Ichihara S, Yamada Y. Genetic factors for human obesity. Cell Mol Life Sci. 2008; 65(7-8): 1086-98.

[3] Baratta M. Leptin - from a signal of adiposity to a hormonal mediator in peripheral tissues. Med Sci Monit 2002; 8: RA282-92.

[4] Karvonen MK, Pesonen U, Heinonen P, et al. Identification of New Sequence Variants in the Leptin Gene. J Clin Endocrinol Metab 1998; 83(9): 3239-42.

[5] Jequier E. Leptin signaling, adiposity, and energy balance. Ann NY Acad Sci 2002; 967: 379-88.

[6] Yiannakouris N, Yannakoulia M, Melistas L, et al. The Q223R polymorphism of the leptin receptor gene is significantly associated with obesity and predicts a small percentage of body weight and body composition variability. J Clin Endocrinol Metab 2001; 86(9): 4434-9.

[7] Chung WK, Power-Kehoe L, Chua M, et al. Exonic and intronic sequence variation in the human leptin receptor gene (LEPR). Diabetes 1997; 46: 1509-1511.

[8] Chagnon YC, Chung WK, Peruse L, et al. Linkages and association between the leptin receptor (LEPR) gene and human body composition in the Quebec Family Study. Int J Obes1999; 23: 278-286.

[9] Chagnon YC, Wilmore JH, Borecki IB, et al: Associations between the leptin receptor gene and adiposity in middleaged Caucasian males from the HERITAGE family study. J Clin Endocrinol Metab 2000; 85: 29-34.

[10] Quinton ND, Lee AJ, Ross RJ, et al. A single nucleotide polymorphism (SNP) in the leptin receptor is associated with BMI, fat mass and leptin levels in postmenopausal Caucasian women. Hum Genet 2001; 108: 233-236.
[11] Silver K, Walstron J, Chung WK, et al. The Gln 223 Arg and the Lys 656 Asn polymorphism in the human leptin receptor do not associate with traits related to obesity. Diabetes 1997; 46: 1898-1900.

[12] Godota T, Manning BS, Goldstone AP, et al. Leptin receptor gene variation and obesity; lack of association in white British male population. Hum Mol Genet 1997; 6: 869-876.

[13] Echwald SM, Sorensen TD, Sorensen TI, et al. Amino acid variants in the human leptin receptor: lack of association to juvenile onset obesity. Biochem Biophys Res Commun 1997; 233: 248-252.

[14] Mergen H, Kaaraslan C, Mergen M, et al. LEPR , ADBR3, IRS1, and 5-HTT genes polymorphism do not associate with obesity. Endocrine Journal 2007; 54(1): 8994.

[15] Slaughter MH, Lohman TG, Boileau RA, et al. Skinfold equations for estimation of body fatness in children and youth. Hum Biol 1988; 60: 709-723.

[16] Ten S, Maclaren N. Insulin resistance syndrome in children. J Clin Endocrinol Metab 2004; 89(6): 2526-2539.

[17] Berenson ML, Levine DM, Goldstein M. Intermediate statistical methods and applications, Prentice-Hall, New Jersey, 1983.

[18] Hosking L, Lumsden S, Lewis K, et al. Detection of genotyping errors by Hardy-Weinberg equilibrium testing. Eur J Hum Genet 2004; 12: 395-399.

[19] Wauters M, Mertens I, Chagnon M, et al. Polimorphism in the leptin receptor gene, body composition and fat distribution in overweight and obese women. Int J Obes Ralat Metab Disord 2001; 25(5): 714-20.

[20] Paracchini V, Pedotti P, Taioli E. Genetics of Leptin and Obesity: A HUGE Review. Am J Epidemiol 2005; 162(2): 101-114.

[21] Endo K, Yanagi H, Hirano C, et al. Association of Trp64Arg polymorphism of the beta3-adrenergic receptor gene and no association of Gln223Arg polymorphism of the leptin receptor gene in Japanese schoolchildren with obesity. Int J Obes Relat Metab Disord 2000; 24(4): 443-9.

[22] Wasik M, Gorska E, Popko K, Pawelec K, Matysiak M, Demkow U. The GLN223ARG polymorphism of the leptin receptor gene and peripheral blood/bone marrow leptin level in leukemic children. J Physiol Pharmacol 2006; 57 Suppl 4: 375-383.

\section{Corresponding author:}

Beata Pyrzak, M.D., Ph.D.

Department of Pediatrics and Endocrinology

Warsaw Medical University

Marszalkowska 24 St.

00-576 Warsaw, Poland

Phone: $\quad+480225227435$

Fax: $\quad+480226214155$

E-mail: b.pyrzak@wum.edu.pl 